\title{
THEORETICAL STRESS-STRAIN MODEL FOR COMPRESSED COMPOSITE CEMENT MATERIALS
}

\author{
IAKOV ISKHAKOV \& YURI RIBAKOV \\ Department of Civil Engineering, Ariel University, Israel
}

\begin{abstract}
Composite cement materials include concrete, reinforced concrete, fibred concrete, etc. The current research is focused on compressed concrete and reinforced concrete elements, loaded by forces, acting without eccentricity. The obtained results will form a basis for developing corresponding models for the above-mentioned materials as well as reinforced cement elements. This problem was investigated experimentally from the first studies on concrete as a composite material. It is still ongoing and attracts many researchers, performing experimental investigation to improve available empirical dependencies. According to modern design codes, the stress-strain diagram for compressed concrete is convex, the ultimate deformations in the plastic stage and in the descending branch are known, concrete behaves at the initial stage as an elastic material, etc. At the same time, there are no exact data on the ultimate elastic stress of concrete and corresponding deformation, ultimate stress of concrete at the descending branch, ultimate linear creep deformations, ductility parameter, etc. The authors have previously developed the structural phenomenon concept that solves the above-mentioned problems. As a result, accurate theoretical stress-strain relationship for compressed concrete is obtained. It also takes into account linear creep of compressed concrete. The theoretical model is recommended for effective design of compressed and bended high performance reinforced concrete elements. The results may also be included in modern codes related to high performance reinforced concrete elements and new cementtype materials.
\end{abstract}

Keywords: composite material, compressed concrete, compressed reinforced concrete, stress-strain diagram, concrete creep.

\section{INTRODUCTION}

A theoretical relationship between stresses and strains of compressed concrete is proposed. It forms a basis for concrete creep and ductility parameters. During the history of reinforced concrete (RC) structures that started with pioneer research of Bach and Graf [1], investigation of this problem is still ongoing. The problem was investigated by leading researchers in this field, like Gvozdev [2], Park and Paulay [3], Wight and McGregor [4], Carreira and Chu [5], etc. These researchers have carried out basic experimental and theoretical investigations that allowed developing modern codes for design of RC structures, for example [6].

Modern codes have a strong experimental background, forming a basis for empirical dependences for the stress-strain curve and modulus of elasticity of concrete. According to these codes, concrete is characterized by the following parameters:

- $\quad$ stress-strain graph for concrete classes up to C50 is usually a convex square parabola, as, according to [6], for these concrete classes the exponent of parabola is constant and equal to 2; ultimate concrete deformations, $\varepsilon_{\mathrm{c} 2}=2 \% 0=$ const and $\varepsilon_{\mathrm{cu} 2}=3.5 \%{ }_{0}=$ const;

- codes don't give the ultimate elastic deformation value, before which the modulus of elasticity remains constant (Fig. 1), but define this value as approximately corresponding to $40 \%$ of concrete strength;

- maximal and ultimate deformations in concrete, $\varepsilon_{c 1}$ and $\varepsilon_{c u 1}$ respectively, are given in Fig. 1 according to [6]. 


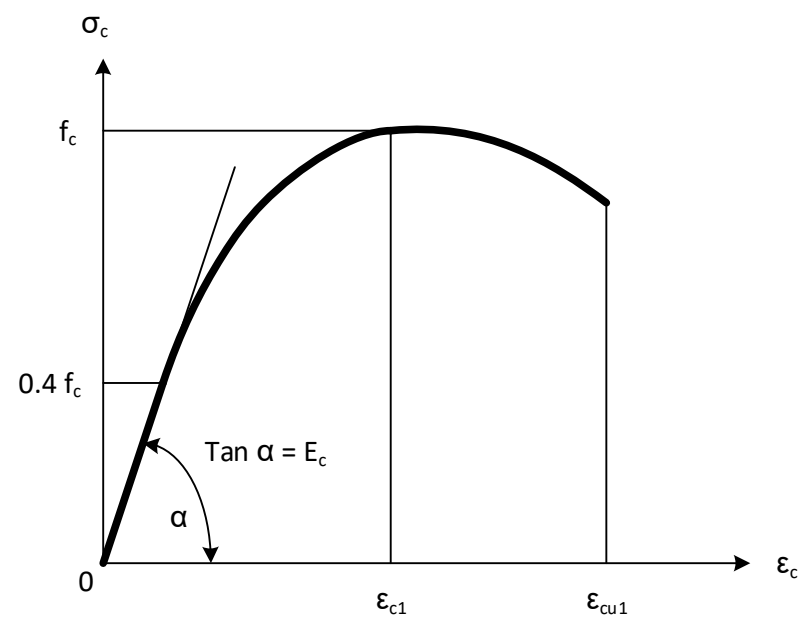

Figure 1: Stress-strain curve for compressed concrete following EC 2 [6].

Theory of concrete is related to the stress-strain dependence, as well as to that between deformations vs. time. These two dependences should be interrelated, as both of them include a common component - concrete deformation $\varepsilon_{c}$. The second dependence is reflected on modulus of deformations of concrete at linear creep. This graph should also allow calculation of linear, plastic and complete potential of concrete. Thus, in spite that the relation $\sigma_{c}$ vs $\varepsilon_{c}$ is rather widely investigated, the above-mentioned problems are still not solved theoretically. The present study is focused on these aspects, based on structural phenomenon [7]. The proposed theoretical solution allows design of new compressed or bended high performance concrete elements without using empirical coefficients, therefore the structures become more effective.

\section{RESEARCH AIMS AND NOVELTY}

The paper is aimed at developing theoretical relationship between stresses and deformations of compressed concrete from initial loading until failure. These parameters include stressstrain relationship, limit of elastic concrete deformations, border between elastic and elasticplastic behavior, concrete stress that corresponds to the descending branch in the stress-strain graph. The study is also focused on concrete modulus of elasticity and modulus of deformations as well as deformations, related to linear creep of concrete and ductility parameters.

The novelty of the present study is that for the first time theoretically based stress-strain relationship without any empirical coefficients is proposed. It is shown, based on the structural phenomenon [7], that this relationship has a descending branch symmetric to the ascending one, the graph satisfies the duality principle. Smoothness and convexity of the stress-strain curve is explained by minimum energy consumption, corresponding to the minimax principle [8].

\section{THE ESSENCE OF STRUCTURAL PHENOMENON}

If a structure is symmetric and the load is also symmetric, usually structural parameters in elastic state increase or decrease twice at failure [7]. The structural phenomenon was analyzed for the following groups of experiments: 
- $\quad$ investigation of structural concrete at material level;

- behavior of RC structures and elements under static loads;

- response of RC structures and elements to dynamic loads.

The phenomenon is based on two fundamental ideas: quasi-isotropic state of a structure at ultimate limit state (ULS) [9] and mini-max principle [8]. Moreover, the phenomenon provides valuable indicators for experiments planning, estimation of structural state (elastic, elastic-plastic, plastic or failure), etc. From the mathematical viewpoint, the phenomenon provides additional equation(s) that enable to calculate parameters, usually obtained experimentally or using some empirical coefficients. The above-described features of structural phenomenon enable to use it in the frame of the present study for obtaining theoretical stress-strain curve of concrete.

\section{MAIN CONCEPTS}

The following theoretical parameters for complete concrete stress-strain relationship are missing:

- $\quad$ maximum elastic deformations of concrete, $\varepsilon \mathrm{c}$ el;

- residual concrete stress, corresponding to deformations $\varepsilon c u 1$ on the descending branch;

- location of the point, separating the elastic and elastic-plastic pieces of the graph $\sigma c$ vs $\varepsilon c$.

Based on the structural phenomenon [7], it is proposed to use a graph, shown in Fig. 2. This graph has the following features:

- the graph is divided into two parts - straight line from point o to point A and square parabolic part $\mathrm{ABC}$;

- point A, separating the linear and parabolic parts of the graph, corresponds to ultimate elastic stress of concrete, $\sigma \mathrm{c}$ el ul, and deformations $\varepsilon \mathrm{c}$ el;

- $\quad$ it is assumed that $\sigma \mathrm{c} \mathrm{el} \mathrm{ul}=0.5 \mathrm{fc}$;

- the descending branch of the graph is symmetric to the ascending one.

Fig. 2 shows that the difference between points $\mathrm{A}$ and $\mathrm{B}$ is equal to that between $\mathrm{B}$ and $\mathrm{C}$ and it is $1.5 \%$. Additionally, point $C$ corresponds to the ultimate concrete stress $0.5 f_{\mathrm{c}}$, which completely satisfies the requirements of the structural phenomenon. Consequently, the maximal elastic deformation of concrete $\varepsilon_{c \text { el }}=0.5 \%$, and the ultimate deformation (see

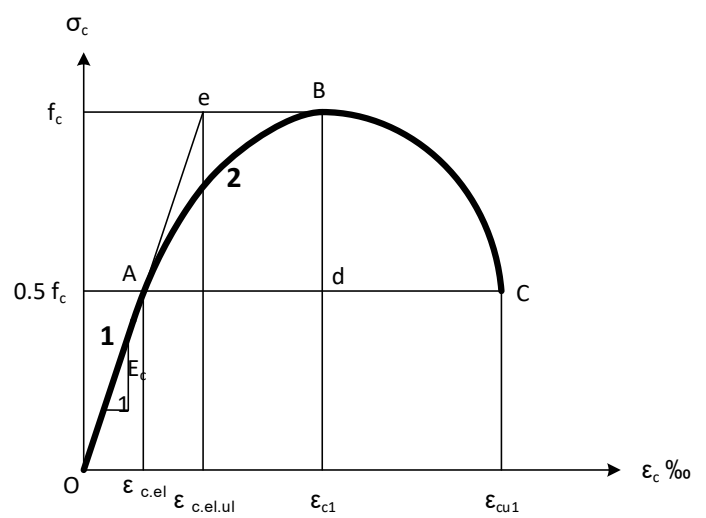

Figure 2: Proposed graph for compressed concrete. 
point e in Fig. 2), $\varepsilon_{\text {cel ul }}=1 \%$. Taking into account that beginning from point $A$ the modulus of elasticity decreases and such decrease cannot be stepped, the straight line oA is tangent to parabola $\mathrm{ABC}$.

\section{STRESS-STRAIN RELATIONSHIP FOR COMPRESSED CONCRETE}

Equation $\sigma_{\mathrm{c}}$ VS $\varepsilon_{\mathrm{c}}$ is developed separately for two pieces of the graph. For the linear piece

$$
0 \leq \sigma_{\mathrm{c}} \leq 0.5 f_{c}, \quad 0 \leq \varepsilon_{\mathrm{c}} \leq \varepsilon_{\mathrm{c} e l}, \quad \mathrm{E}_{\mathrm{c}}=\sigma_{\mathrm{c}} / \varepsilon_{\mathrm{c} e l} .
$$

The parabolic part of the graph is given as follows:

$$
0.5 f_{c} \leq \sigma_{\mathrm{c}} \leq f_{\mathrm{c}}, \quad \varepsilon_{\mathrm{c} e l} \leq \varepsilon_{\mathrm{c}} \leq \varepsilon_{\mathrm{cl}}, \quad \mathrm{E}_{\mathrm{c}}=\mathrm{d} \sigma_{\mathrm{c}} / \mathrm{d} \varepsilon_{\mathrm{c}} .
$$

The equation, corresponding to square parabola $\mathrm{ABC}$, is:

$$
\Sigma_{\mathrm{c}}=a \varepsilon_{\mathrm{c}}^{2}+b \varepsilon_{c}+c,
$$

where coefficients $a, b$ and $c$ are obtained from the following three conditions:

- $\quad$ at point $\mathrm{A} \sigma_{\mathrm{c}}=0.5 f_{\mathrm{c}}, \varepsilon_{\mathrm{c}}=\varepsilon_{\mathrm{c} e l}$;

- $\quad$ at point $\mathrm{B} \varepsilon_{\mathrm{c}}=\varepsilon_{\mathrm{c} 1}, \sigma_{\mathrm{c}}=f_{\mathrm{c}}$;

- $\quad$ at the same point $\mathrm{E}_{\mathrm{c}}=0$.

Therefore, eqn (3) takes the following form:

$$
\sigma_{\mathrm{c}} / f_{c}=1-0.5\left(\varepsilon_{\mathrm{c} 1}-\varepsilon_{\mathrm{c}}\right)^{2} /\left(\varepsilon_{\mathrm{c} 1}-\varepsilon_{\mathrm{c} e l}\right)^{2} .
$$

Modulus of elasticity, $E_{c}$, for the elastic deformations range is given by eqn (1). The initial value of $E_{c}$ is taken according to modern codes, for example [6]. However, the value of concrete elastic deformations is not specified in the codes. It is possible to calculate concrete elastic deformations as follows:

$$
\varepsilon_{\mathrm{c}}=0.5 f_{\mathrm{c}} / \mathrm{E}_{\mathrm{c}}
$$

The first derivative of eqn (4) enables to obtain the values of concrete modulus of deformability, $\mathrm{E}_{\mathrm{c}}$. Concrete stress-strain relationship includes also elastic and elastic-plastic potential of compressed concrete that can be expressed by ductility parameter. Fig. 3 shows an elastic potential of compressed concrete, $\mathrm{U}_{e l}$ (shaded area), which equals to:

$$
\mathrm{U}_{\mathrm{el}}=\mathrm{A}_{\mathrm{oA} a}+2 \mathrm{~A}_{\mathrm{ABd}}=0.25 f_{c}\left(2 \varepsilon_{\mathrm{c} 1}-\varepsilon_{\mathrm{c} e l}\right) \text {. }
$$

For $\varepsilon_{\mathrm{c} 1}=2 \%$ and $\varepsilon_{\mathrm{c} e l}=0.5 \%$ o (see Fig. 3)

$$
\mathrm{U}_{e l}=0.25 f_{c}(22-0.5)=0.875 f_{c} \% \text {. }
$$

Plastic potential of compressed element can be calculated as follows:

$$
\mathrm{U}_{p l}=2 \mathrm{~A}_{\mathrm{AgB}}+2 \mathrm{~A}_{a \mathrm{AdB}}=1.167 f_{c}\left(\varepsilon_{\mathrm{c} 1}-\varepsilon_{\mathrm{c} e l}\right) .
$$

At $\varepsilon_{\mathrm{c} 1}=2 \%, \varepsilon_{\mathrm{c} e l}=0.5 \%$

$$
\mathrm{U}_{p l}=1.75 f_{c} \% \text { ). }
$$

Then from eqns (7) and (9) follows that

$$
\mathrm{U}_{p l} / \mathrm{U}_{e l}=1.75 f_{c} \%_{0} / 0.875 f_{c} \% \mathrm{o}=2 .
$$

This result completely corresponds to the structural phenomenon [7].

Ductility parameter

$$
\mu=1+\mathrm{U}_{p l} / \mathrm{U}_{e l}=1+2=3 .
$$




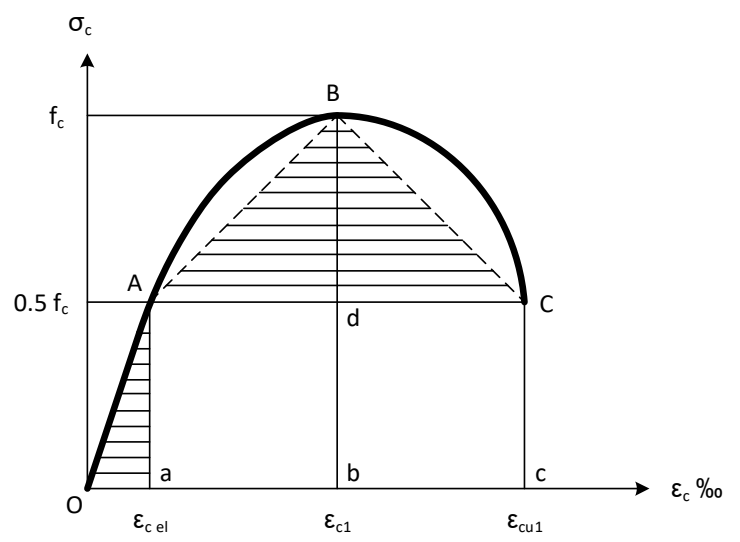

Figure 3: Elastic potential of compressed concrete (shaded area).

Linear creep of concrete exists in the range of concrete compression stresses

$$
0 \leq \sigma_{\mathrm{c}} \leq 0.5 f_{c} .
$$

Taking into account that concrete stress at creep remains constant, linear creep yields that the concrete modulus of elasticity reduces twice [7]

$$
\mathrm{E}_{\mathrm{c} c r}=0.5 \mathrm{E}_{\mathrm{c}} \text {. }
$$

In modern design codes linear creep of concrete is considered by creep coefficient, $\varphi_{\mathrm{c} \mathrm{cr}}[6]$

$$
\varepsilon_{\mathrm{c} c r}=\varphi_{\mathrm{c} \mathrm{cr}} \varepsilon_{\mathrm{c}} .
$$

For example, creep coefficient values, according to [6], are presented in Table 1. As it follows from this table, the average creep coefficient for 90 days loaded concrete element is equal to 2, which corresponds to the structural phenomenon [7].

\section{COMPRESSED REINFORCED CONCRETE ELEMENT}

As known, concrete compression strength is about 10-20 times lower compared to steel. However, the part of load, transferred to compressed reinforcement is much lower than that, obtained by concrete. It is because the reinforcement ratio in compressed concrete is rather low and is about $\rho=0.5 \%$. Therefore, the reinforcement bars get a force that equals

$$
\mathrm{N}_{\mathrm{s}}=\rho \mathrm{A}_{\mathrm{c}} f_{\mathrm{s}}=0.005 \mathrm{~A}_{\mathrm{c}} 400=2 \mathrm{~A}_{\mathrm{c}} .
$$

Table 1: Linear creep coefficient values for relative humidity of 50\% (following [6]).

\begin{tabular}{|c|c|c|c|c|}
\hline \multirow{2}{*}{$\begin{array}{c}\text { Age of the } \\
\text { element at } \\
\text { loading, days }\end{array}$} & \multicolumn{2}{|c|}{ Equivalent concrete element thickness, mm } & \multirow{2}{\text{Averagevalue}}{$\begin{array}{c}\text { of creep } \\
\text { coefficient }\end{array}$} \\
\cline { 2 - 4 } & 50 & 150 & 600 & 2.5 \\
\hline 28 & 3.0 & 2.5 & 2.0 & 2.0 \\
\hline 90 & 2.4 & 2.0 & 1.6 & 1.5 \\
\hline 365 & 1.8 & 1.5 & 1.2 & \\
\hline
\end{tabular}


The force transferred to concrete

$$
\mathrm{N}_{\mathrm{c}}=\mathrm{A}_{\mathrm{c}} f_{c}=20 \mathrm{~A}_{\mathrm{c}}
$$

where $A_{c}$ is the concrete section area.

It means that even in the case of low concrete class (C20) concrete takes 10 times more than steel

$$
\mathrm{N}_{\mathrm{c}} / \mathrm{N}_{\mathrm{s}}=20 / 2=10 .
$$

In any case, following the structural phenomenon [7],

$$
\mathrm{N}_{\mathrm{c}} \geq \mathrm{N}_{\mathrm{s}}, \quad \mathrm{N}_{\mathrm{c}} \geq \mathrm{N} / 2,
$$

where $\mathrm{N}$ is the axial force.

Common work of compressed concrete and reinforcement requires equal strains:

$$
\varepsilon_{\mathrm{c}}=\varepsilon_{\mathrm{s}}{ }^{\prime} \text {. }
$$

As it was mentioned above, the square parabola, describing the $\sigma_{\mathrm{c}}-\varepsilon_{\mathrm{c}}$ relationship, corresponds to the following expression

$$
\sigma_{\mathrm{c}}=1000 f_{c} \varepsilon_{\mathrm{c}}\left(1-250 \varepsilon_{\mathrm{c}}\right) .
$$

From this equation follows that

$$
\varepsilon_{c}=\frac{1-\sqrt{1-\sigma_{c} / f_{c}}}{500}=\varepsilon_{s}^{\prime} .
$$

In this equation $\varepsilon_{s}^{\prime}$ is in \%o, therefore eqn. (21) can be re-written as follows

$$
\varepsilon_{s}^{\prime}=2\left(1-\sqrt{1-\sigma_{c} / f_{c}}\right) .
$$

A corresponding graph is shown in Fig. 4. Following this graph, compressed reinforcement behaves similar to compressed concrete.

\section{INFLUENCE OF DYNAMIC LOADING ON COMPRESSED CONCRETE ELEMENT}

In the first loop due to dynamic loading concrete behaves as linear elastic material from $\sigma_{\mathrm{c}}=0$ to $\sigma_{\mathrm{c}}=0.5 f_{c}$ (Fig. 5). Between $\sigma_{\mathrm{c}}=0.5 f_{c}$ and $\sigma_{\mathrm{c}}=f_{c}$ concrete behaves as linear material with reduced modulus of elasticity, but the maximum deformation value remains constant as at static loading, i.e. $2 \%$. In the end of the first loop the deformation is equal to 0 and part $\mathrm{CD}$ in the graph is parallel to linear elastic stage $\mathrm{OB}$. As concrete contribution in tension is negligible, the graph goes from $\mathrm{D}$ to $\mathrm{O}$ along the horizontal axis.

The second loop begins also from point $\mathrm{O}$, but goes linearly to point $\mathrm{C}$ and after that it continues plastically to point E. From this point starts unloading along line EF, which is parallel to OC. From point F, the graph returns to point $\mathrm{O}$, like in the first loop.

The third and last loop starts again from point $\mathrm{O}$. It goes linearly along line $\mathrm{OE}$ and after reaching point $\mathrm{E}$, corresponding to maximal deformation $\varepsilon_{\mathrm{c}}=2.75 \%$, continues plastically (parallel to the horizontal axis) up to reaching the ultimate deformation $\varepsilon_{\mathrm{cu} 2}=3.5 \%$.

\section{CONCLUSIONS}

A theoretical stress-strain relationship for compressed concrete classes C20-C50 that considers linear concrete creep is obtained. It is proposed to use a compressed concrete and reinforced concrete stress-strain relationships that have the following new features, corresponding modern high performance concrete elements and structures: 
High Performance and Optimum Design of Structures and Materials III 15

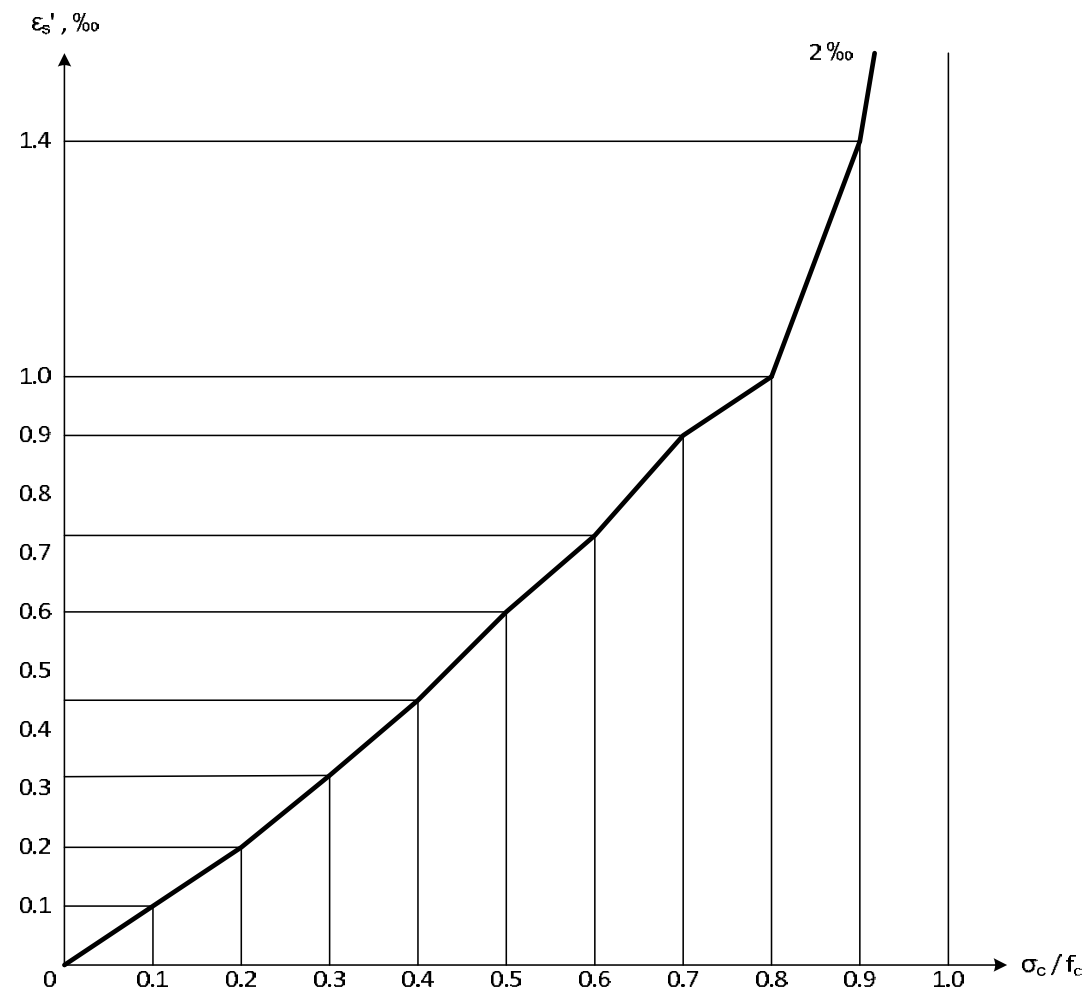

Figure 4: Dependence between $\varepsilon_{\mathrm{s}}^{\prime}$ and $\sigma_{\mathrm{c}}$.

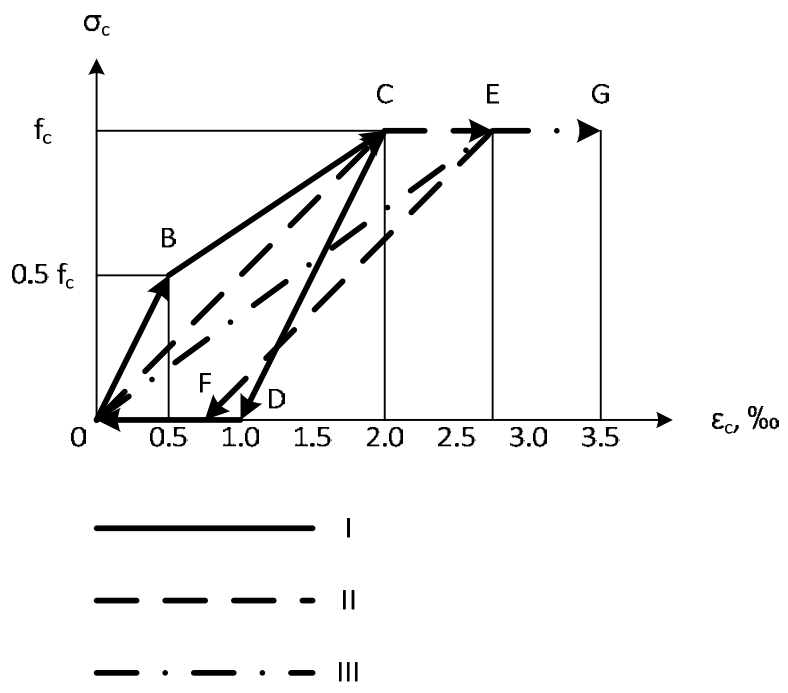

Figure 5: Hysteretic behavior of compressed concrete. 1 - first loop; 2 - second loop; 3 - quarter of the third loop. 
- $\quad$ the graph is divided into two parts - straight line and square parabola;

- a point, separating the linear and parabolic parts of the graph, corresponds to ultimate elastic stress and deformation of concrete;

- $\quad$ the maximum elastic deformations of concrete correspond to $0.5 f_{\mathrm{c}}$;

- the descending branch of the graph is symmetric to the ascending one.

Concrete stress-strain relationship includes elastic and elastic-plastic potential of compressed concrete, expressed by ductility parameter that equals 3 .

It is shown that according to structural phenomenon, linear creep of concrete causes decrease of the modulus of elasticity up to twice. The maximal value of the linear concrete creep coefficient is 2 .

The proposed new approach forms a basis for more effective design of high performance reinforced concrete structures. It is suitable for compressed elements as well as compressed section zone of bended ones. The most important advantage of the approach is avoiding the use of empirical coefficients in the stress-strain relationship of concrete.

\section{REFERENCES}

[1] Bach, C. \& Graf, O., Tests with simply supported, quadratic reinforced concrete plates. Deutscher Ausshuss für Eisenbeton, 30, 1915. (In German.)

[2] Gvozdev, A.A., Obtaining the destructive loads value for statically indetermined systems under plastic deformations. Proceedings of the Conference on Plastic Deformations, Russian Academy of Sciences, Moscow, 1938. (In Russian.)

[3] Park, R. \& Paulay, T., RC Structures, J. Wiley and Sons: New York, London, Sydney \& Toronto, 1975.

[4] Wight, J.K. \& McGregor, J.G., Reinforced Concrete Mechanics and Design, 6th ed., Pearson Education: New Jersey, 2012.

[5] Carreira, D.J. \& Chu, K.H., Stress-strain relationship for plane concrete in compression. ACI Journal, 82(6), pp. 797-804, 1985.

[6] Eurocode 2: Design of Concrete Structures - Part 1-1: General Rules and Rules for Buildings, 2004.

[7] Iskhakov, I. \& Ribakov, Y., Structural phenomenon of cement-based composite elements in ultimate limit state. Article ID 4710752. Advances in Materials Science and Engineering, 2016. DOI: http://dx.doi.org/10.1155/2016/4710752.

[8] Iskhakov, I. \& Ribakov, Y., Ultimate Equilibrium of RC Structures using Mini-Max Principle, Nova Science Publishers, 2014.

[9] Iskhakov, I., Quasi-isotropic ideally elastic-plastic model for calculation of RC elements without empirical coefficients. Structural Engineering, Mechanics and Computation, Volume I, ed. A. Zingoni, Elsevier Press, pp. 367-374, 2001. 